\title{
University Libraries and University Research
}

Since a university library is a service agency, it is unable itself to " $r a$ tionalize" the potentially limitless demands made upon it by the sum of requests from individual researchers. Theoretically its budget demands on the institution could potentially be limitless. The library is involved in two "information cycles": a "publication cycle" of production of new knowledge, its formalization and its storage and use; and $a$ "demand cycle." Both of these cycles involve institutional cost. Rationalization decisions can be made at a program level, when the institution decides whether to enter a subject area; or at a recruitment level, when the institution and a candidate for a staff position decide whether there is a "match" of interests. Upon recruitment, the institution has a responsibility to support the staff member's research interests.

\begin{abstract}
UR CONCERn is the Relationship between the development of research resources in university libraries and the initiative of the researcher toward projects. Arising from this is the cost, to both individual institutions and to regional systems of libraries or institutions, and ultimately to the (governmental) funding agency. Our concern is the conflict which occurs, so often as to be the rule, between the location of
\end{abstract}

This paper was originally presented as $a$ brief to the Commission to Study Rationalization of University Research, of the Association of Universities and Colleges of Canada, at a hearing December 10, 1971. The authors gratefully acknowledge the valuable assistance of Ms. Lin Good, Rudolf C. Ellsworth, William F. E. Morley, and Theodore D. Phillips. All are members of the staff of Douglas Library, Queen's University at Kingston, Ontario. The opinions expressed are those of the respondents and not those of the university. research and the location of resources: the one ever varying, the other often underused. Our contention is that unless rationalization decisions are applied in two ways, university libraries are faced with a limitless expansion and needless duplication of efforts to build resources. Those two ways are: (1) rationalization decisions at the institutional level to delimit areas of interest and acceptance by the individual of limits to the resources which can be provided for him; and (2) the cooperative interinstitutional approach to information resources, which will make possible rationalization decisions about the relocation of library resources.

Library resources are gathered, in the first place, in response to current teaching and research demands. They necessarily represent commitments to research. The cost of acquiring and organizing a collection sufficient for even the smallest research project is very large, in time as well as money. A col- 
lection once gathered, though it be unused because of changing research interests, represents a continuing charge to the institution for storage and service.

Instances are rare in which an individual or a research group is drawn to an institution because its library research resources are attractive. So few institutions are fortunate enough to own collections attractive to researchers in many disciplines that the phrase "Harvard effect" is obvious in meaning. By-andlarge, established collections are not the impetus to research. Rather, the researcher generates a demand post facto upon the library. The alternative possibility-that the individual's research will be limited to available materialsis much less likely.

The unpredictable, "mosaic" nature of the choice of individual research topics means that many very small areas may be intensively studied, and resources on those topics in demand for a time; while other areas are untouched, and sparse or fallow in the library. The informational material used for research is typically so specialized that the statistically predictable frequency of use, well documented by Ash, Trueswell, and many others, is very low-on the order of once in several years. ${ }^{1,2}$ Whether large or small collections of research material are gathered they will both have a low probability of continuing use. Clearly, for economy of research resources, the probability of use should be increased-by making the resources available to the largest community of researchers; by increasing the continuity of research interest; or by rationalization decisions which channel the development of these resources in the first instance.

\section{The Research Information Cycle}

Figure 1 illustrates a well-known phenomenon which we shall here call the research information cycle. The stages by which research conclusions are disseminated proceed by increasing formalization: from the stage of personal communication to a known colleague, through oral group communication (lectures to meetings), to what the scientist calls the "primary literature." This is in turn extracted and compiled, becomes standard fact, and is superseded (becomes obsolescent) by new research. ${ }^{3,4}$

The library is the formal repository for information in the generic sense. If the information is numeric or unpublished or ephemeral, the repository may be called a documentation or information analysis center, or data bank, but the substitution or the interpolation of an information analyst-a surrogate researcher-does not affect the form of the cycle. A library (or its kin) is central to the cycle.

This is an open cycle. By the time information has gone through the successive stages of publication, the researcher himself is no longer interested in it. Information is of the greatest use to him when provided through the shortest path. No wonder that the largest reliance is on the "invisible college"-personal contact accounting for the largest fraction of information supply.

Because this is an open cycle, one must ask whether rationalization of research is a means of closing or recurving the cycle to reenter a prior stage. Rationalization is shown in Figure 1 as impinging upon the researcher. Proceeding around the cycle through the stages of formal publication, rationalization could take the form of controlling publication or distribution; of evaluating literature resources, both those in the library and those not available; and of choosing areas to be included or excluded when setting the scope of research interests.

The library itself cannot make those rationalization decisions. The demand upon it is potentially limitless. By definition it is a service; only if the demand 


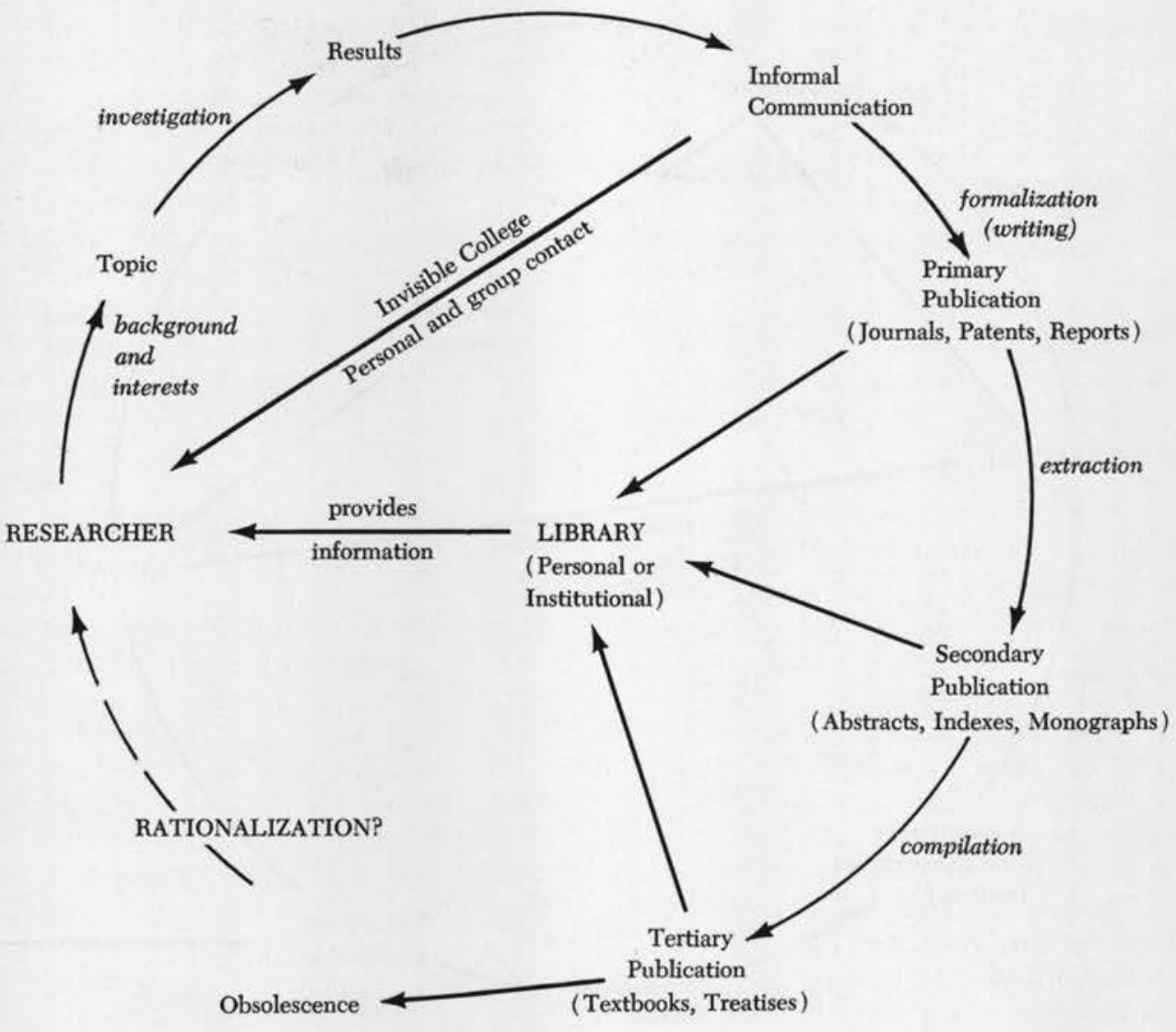

Figure 1

The Research Information Cycle:

Generation and Recycling of Information (the Publication Cycle)

is given limits can the library attempt to satisfy all users.

The relationship between researcher and library is further shown in Figure 2. The horizontal diameter (provision of information from library to researcher) has already appeared in Figure 1 , the information cycle. In Figure 2 , the generation of information demand by the interests of the individual can be seen to result in increased competition for finance, and in a budget demand by the library upon the institution's administration. ${ }^{5}$ The rationalization decision which will limit these demand flows must therefore be made by the individual, before he decides upon his research, or by the institution, either before or after the individual has committed his personal resources.

To reiterate, the library cannot make these rationalization decisions. As a service agency, it can only satisfy demands, or explain why it fails to satisfy them. The explanations are presumptive, and the researcher should accept them and temper his demands accordingly, or seek elsewhere to influence budget decisions.

Teaching, Research, and Mobility

We accept the reality that research and teaching demands upon the library 


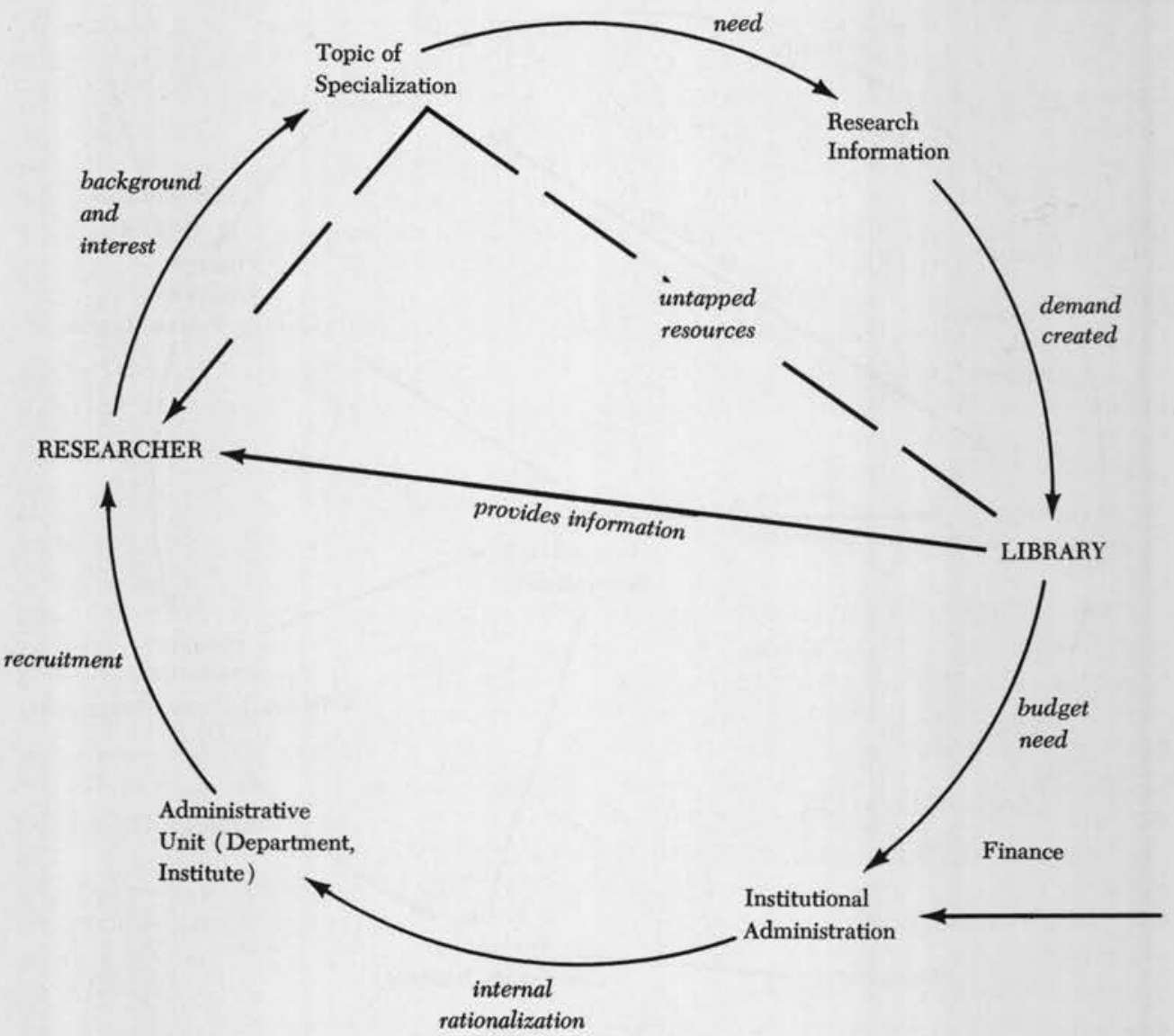

Figure 2

The Research Information Cycle and the University Library: the Demand Cycle

are so closely linked that one is unable to distinguish between acquisitions made for the one purpose and for the other. A preliminary study at our institution (not yet available for release) tends to confirm this; the opinion of teaching staff is that their research makes a relatively small incremental demand upon the library, over that of their (graduate) teaching.

Because an individual moves not only among several institutions in a typical career, but more importantly from project to project, the probable consequent use of particular specialized library re- sources may wane in a year, or in a few years. He may commit the institution directly to large library expenditures, and indirectly to equally high salary and service costs, while engaged in closely-related teaching and research, and depart, metaphorically or bodily, for other pastures after a few years.

This cost can be looked upon in two ways: as a necessary capital expenditure associated with the decision to engage in some new research program, and thereafter to be treated as a sunk cost; or as a capital investment (in the individual) for which a return must be 
computed. The return to the institution and to society upon such investment is known to be small. We may hypothesize that in many instances the investment is never fully repaid. The larger part of the return is to the researcher in the form of prestige and salary increases.

We prefer to treat expenditure on library resources as investments rather than sunk costs, because they involve continuing service (housekeeping) costs to the institution. We ask then how the return on such investments can be increased. Clearly, by increasing continuity of interest in them, increasing the number of potential users, or by locating the resources where either of the first two factors can operate.

We see no reason not to treat the information cycle as operative at regional or national levels. The implication is that the researcher and the institution must consider the location of library resources at these levels before making a decision to engage in particular research. Institutional administrations should encourage researchers to undertake their work in the places where resources exist, possibly unused. Alternatively, we recommend that, so far as possible within the framework of institutional and provincial rights, library resource strengths be relocated to suit the needs of research, rather than unnecessarily duplicated. There are costs and technical problems associated with such activity, but we believe them to be less than the cost of unrationalized and uncoordinated activity.

\section{DECISION-MAKING IN THE InSTITUTION}

Two types of impetus for research can be identified: individual initiative, and the research-oriented group. The group may be based on a teaching program, a primary research purpose, or an administrative unit such as a teaching department or school.

The group may have a direct impact on the library if their decision is to mount a program which will require library resources and services. The impact may be indirect if the decisions made delimit individual interests, involve recruitment or the selection of the researchers themselves. How are these administrative decisions and interests generated? How are they sanctioned by the institution, and at what level? Frequently they are "sparked" by a strong individual, around whom a group clusters, from which a formal program proposal may eventually evolve.

It has been our experience that a curricular decision made within a teaching department is often determined without adequate consideration both of available library resources, and of cost and lead time required to develop needed resources. Program decisions, at least at the graduate level in Ontario, now involve formal communication with the library, and a lead time of nearly two years for the whole process. This is a decided help.

The pure research decision at the group level may not consider library resources in advance at all; yet it is likely to have the largest cost because the informational resources needed are primary, sometimes unique, costly, extensive, and always highly intensive. The well-known Bradford-Zipf Law of Distribution of Informational Resources in a subject demonstrates that to be exhaustive in even a narrow topic requires a very large coverage of the literature.

Has the individual a "right" to do research? We would point out that members of an institution agree to operate within preestablished regulations; they agree at least to certain limits to other "rights." These limitations in no way affect academic freedom to inquire as the individual wishes. Rather, there are economic realities which may limit the depth to which a research project may be pursued, indeed sometimes precluding it altogether.

As part of the recruiting process by 
which an individual comes to an institution, the candidate has an obligation to explore its existing resources, as well as to make his interests known. The administrator who does the recruiting has an obligation to test the "fit" or "match" between the institution's needs and the individual's potential-and also between the individual's research interest and the institution's potential. The crucial question should be: what obligations, immediate and continuing, must the institution take on; what must be promised him, if he comes here? The individual should be introduced to unexplored resources in his general area, with the possibility that his research interests may be enlivened. The library often assists a graduate student in finding a thesis topic; how often has this occurred in the case of a staff researcher?

After the "match" is accepted, the institution has at least a limited obligation to provide resources for the individual's research. The department (or other unit) must ensure that this provision is made-not by coercion of, but by cooperating with the library to explain its needs to the administration. If promises are made they must be kept, but if the library has not made the promise, it should be under no stringent obligation to shift its budget and make such provision.

For his part, the individual should consider whether his "right" to do research yields precedence to the obligations of the program in which he participates, or the limits of scope of the institution he has agreed to join. When a program-level decision for research has been made, the institution (since it has a larger power of review over the decision) has the larger responsibility to support it.

Vertical divisions between parts of the university-departments, institutes, faculties, schools-cause a lack of internal rationalization. Such hiatus of structure means that the university tends to add programs, projects, courses, or research interests without its own organic wholeness in clear view. Individual units support this autonomy of aims, supporting each others' rights to determination, rather than the integrity of the whole. This is a core problem of rationalization: it must be internal as well as external; within the institution, as well as among institutions. Rationalization must also exist interinstitutionally within any given discipline.

\section{SumMaRY AND RECOMMENDATIONS}

We would summarize points which we have tried to make evident:

1. Failing rationalization, university libraries face limitless demands.

2. Libraries cannot make rationalization decisions since they are service agencies.

3. The researcher generates a demand, but there is no overall pattern to the sum of demands.

4. Common to the cycle of the generation and dissemination of information, and the cycle of research demands within an institution, is the library-researcher axis-that of the provision of information.

5. Individuals are mobile both physically and in research interests.

6. Library resources should be considered investments, rather than sunk costs, and an effort made to increase the return by encouraging use.

7. Return on library resources can be increased by:

(a) increasing continuity of interest (probably at the program level);

(b) increasing the number of potential users, by regional availability;

(c) locating the resources for best use, by transfer if need be;

(d) encouraging researchers, especially recruits, to explore available but underused resources.

8. Rationalization decisions are necessary within an institution as well as 
among institutions; among the various groups in a university, as well as among like groups in various universities.

9. Rationalization decisions are possible particularly:

(a) in the recruitment process for researchers;

(b) at the program level.

10. Program and research decisions involve a library factor, with cost and lead-time components, for which a positive mechanism should be included in the decision procedure.
11. The individual's "right" to do research may be constrained by cost problems.

12. The faculty recruit and the administrator have an obligation to test the match of interests and potential, and of available resources and budget; and having accepted the match, reconcile themselves to such limits.

13. The institution, having accepted an individual, has within cost limits an obligation to support his interests, including research.

\section{REFERENCES}

1. Lee Ash, Yale's Selective Book Retirement Program. Hamden, Conn.: Archon Books, 1963.

2. Richard W. Trueswell, "Two Characteristics of Circulation and Their Effect on the Implementation of Mechanized Circulation Control Systems." CRL 25, no. 4 (July 1964), p. 285-91.

3. S. C. Bradford, Documentation. London: Crosby Lockwood, 1948.

4. G. K. Zipf, Human Behavior and the Principle of Least Effort. Cambridge, Mass.: AddisonWesley, 1949. 